\title{
Rancang Bangun Sistem Monitoring Arus Bocor Isolator
}

\author{
Yusrianto Malago ${ }^{1}$, Stephan Adriansyah Hulukati ${ }^{2}$, Amelya Indah Pratiwi ${ }^{3}$ Lanto Muh.Kamil Amali ${ }^{4}$ \\ ${ }^{123}$ Jurusan Teknik Elektro Universitas Ichsan, Gorontalo \\ ${ }^{4}$ Jurusan Teknik Elektro Universitas Negeri Gorontalo \\ Jl. Ahmad Nadjamuddin No.17 Gorontalo 35145 \\ lamelyaindahpratiwi@gmail.com \\ ${ }^{2}$ stephanhulukati@gmail.com \\ ${ }^{3}$ yusrianto_malagoelive.com
}

Intisari - Salah satu peralatan penting dalam sistem ketenagalistrikan adalah isolator yang berfungsi sebagai penyekat bagian bertegangan dan tidak bertegangan agar tidak terjadi aliran listrik yang berdampak pada pemadaman listrik, kebakaran dan korban jiwa. Penelitian ini bertujuan untuk merancangg sistem monitoring arus bocor isolator menggunakan sensor arus CST013 dan nodeMCU ESP8266 dan Thingspeak sebagai media monitor arus bocor yang terukur. Metode penelitian dimulai dari perancangan sistem, pembuatan prototipe, pengujian isolator dengan tegangan tinggi $\mathrm{AC}$ mulai dari $5 \mathrm{kV}$ sampai terjadi flashover pada isolator uji. Pembacaan arus bocor oleh sensor dibandingkan dengan hasil pembacaan arus oleh multimeter. Sensor arus mulai mendeteksi arus bocor pada menit 17:41:24 sebesar 0,001 pada tegangan uji $35 \mathrm{kV}$ dan nilainya semakin meningkat sebanding besarnya tegangan uji dan lamanya pengujian isolator.Arus bocor tertinggi yang terukur oleh sensor terjadi pada saat isolator mengalami flashover yakni sebesar 1,932 Ampere pada tegangan uji $70 \mathrm{kV}$.Selisih pembacaan arus oleh sensor dan multimeter pada masing-masing tegangan uji $30 \mathrm{kV}, 50 \mathrm{kV}, 70 \mathrm{kV}$ adalah $0,032 \mathrm{~A}, 0,108 \mathrm{~A}, 0,310 \mathrm{~A}$.

Kata kunci - arus bocor, sensor arus, nodeMCU, thingspeak, isolator.

Abstract - One of the important equipment in the electricity system is an insulator that works as an insulator of the live and non-voltage parts so that there is no electricity flow that has an impact on power outages, fires and fatalities. This study aims to design an isolator leakage current monitoring system using a current sensor CST013 and nodeMCU ESP8266 and thingspeak as a medium for monitoring excess leakage current. The research method starts from system design, prototype making, insulator testing with high voltage AC starting from $5 \mathrm{kV}$ until a flashover occurs on the test insulator. The leakage current reading by the sensor is compared with the current reading by the multimeter. The current sensor starts detecting leakage current at 17:41:24 minutes of 0.001 at a test voltage of $35 \mathrm{kV}$ and the increase increases in proportion to the test voltage and the insulator test. The highest leakage current achieved by the sensor occurs when the insulator flashover is 1,932 Ampere in the $70 \mathrm{kV}$ test. The difference between reading the current by the sensor and multimeter at each test voltage of $30 \mathrm{kV}, 50 \mathrm{kV}, 70 \mathrm{kV}$ is $0.032 \mathrm{~A}, 0.108 \mathrm{~A}, 0.310 \mathrm{~A}$ Keywords - leakage current, current sensor, NodeMCU, thingspeak, isolator. 


\section{PENDAHULUAN}

Isolator adalah salah satu peralatan yang berperan penting dalam menjamin kontinuitas pelayanan listrik, keamanan sistem dan keamanan manusia dalam proses penyaluran listrik dari pembangkit sampai ke pelanggan listrik. Isolator berfungsi sebagai penyekat antara bagian yang bertegangan dan tidak bertegangan maupun pemisah antara bagian-bagian peralatan yang bertegangan.

Kegagalan kerja isolator berdampak pada pelayanan penyaluran listrik seperti pemadaman, kebakaran, kesetrum yang mengakibatkan kerugian materil dan korban jiwa. Terdapat banyak kasus kebakaran Gardu Induk listrik di Indonesia yang disebabkan tegangan tinggi lebih sambaran petir dan arus bocor yang tidak mampu diatasi oleh sistem proteksi. Seperti kasus kebakaran gardu induk Gambir milik PT.PLN yang diberitakan koran Online Tempo 13 Januari 2020. Kasus kebakaran Gardu listrik di Kota Batam tahun 2013 akibat sambaran petir di gardu listrik (detik news, 2013) yang menyebabkan puluhan rumah terbakar serta masih banyak lagi kasus kebakaran gardu listrik yang disebabkan kegagalan sistem proteksi listrik.

Pengujian kekuatan dielektrik isolator yang dilakukan di Laboratorium Teknik Tegangan Tinggi Universitas Negeri Gorontalo dengan mengukur nilai tegangan lompatan api (flashover) dan arus bocor menggunakan alat ukur voltmeter dan multimeter. Pengambilan data arus bocor menjadi sulit dilakukan karena waktu pembacaan nilai arus pada multimeter sangat cepat hitungan detik akan hilang dari layar. Mahasiswa juga kesulitan memantau kapan arus bocor mulai terjadi pada isolator yang diuji karena kendala sulitnya pembacaan di layar yang mana multimeter dipasang di dalam lemari pengujian yang dibatasi besi penyekat antara peralatan pengujian tegangan tinggi dan bagian lain termasuk manusia demi keamanan dan keselamatan pengguna dan sistem.

Kendala ini semakin terasa sulit untuk mahasiswa tugas akhir yang mengambil topik kekuatan dielektrik isolator, atau pengujian tegangan tinggi peralatan isolasi.
Membutuhkan lebih dari satu orang untuk pengambilan data tegangan dan arus bocor secara bersamaan. Belum lagi mereka butuh mengambil dokumentasi pengambilan data pengujian sehingga tugas akhir oleh seorang mahasiswa membutuhkan bantuan minimla 2-3 orang pada proses pengambilan data.

Diperlukan suatu sistem monitoring arus yang memudahkan pengambilan data dilaboratorium tegangan tinggi. Sistem monitorng akan mengukur arus yang mengalir pada permukaan isolator secara real time dan menampilkan hasilnya pada layar komputer operator lab.

Oleh karena itu, pada penelitian ini dibuat rancang bangun prototipe sistem realtime monitoring arus bocor pada isolator dengan menggunakan sensor arus, NodeMCU ESP 8266 dan menggunakan plat form thingspeak sebagai monitor arus yang akan memudahkan pengambilan data arus bocor di laboratorium tegangan tinggi Universitas Negeri Gorontalo.

Beberapa hasil review kami pada artikelartikel jurnal yang juga menggunakan sensor arus dan nodeMCU ESP8266 diantaranya yakni : Penelitian yang dilakukan oleh [1] dengan membuat sistem monitoring arus bocor pada screen kabel tanah yang terpasang di sisi outgoing transformator. Dengan adanya sistem dan prototipe tersebut sehingga dapat diketahui adanya arus bocor yang mengalir pada permukaan kabel tanah yang terpasang pada Gardu Induk. Microcontroller yang digunakan adalah Atmega 16 dan sensor arus serta sistem dihubungkan dengan jaringan wifi sehingga data dan intruksi dapat dilakukan sampai radius 60 meter tanpa penghalang.

Penelitian yang dilakukan [2] merancang sebuat sistem monitoring konsumsi energi listrik berbasis mikrokontroler Atmega 238 dan sensor arus ACS 712. Tingkat kesalahan pembacaan arus pada beban yang resistif < $1 \%$, lampu LED 14,3\%, dan lampu philips sebesar 5,73\%. Penelitian [3] membuat sistem monitoring tegangan, arus dan daya listrik yang dapat diakses dengan internet. Tingkat ketelitian sistem dengan watt meter sebesar $90 \%$ lebih. Dengan persentase error berkisar 2,96\% - 7,28\%. 
Ada banyak penelitian tentang sistem monitoring dan implementasinya pada berbagi bidang termasuk yang akan kami terapkan namun penerapan dibidang isolator belum pernah dilakukan oleh peneliti lain.

Isolator adalah peralatan listrik yang tidak dapat menghantarkan arus listrik sehingga digunakan sebagai penyekat bahan konduktif. Kemampuan isolator untuk tidak mengalirkan arus dapat diketahui dengan pengujian tegangan tinggi yang diterapkan pada isolator sampai isolator tersebut tembus tegangan dan arus bocorpun mengalir. Ada banyak faktor yang dapat membuat isolator mengalami penurunan nilai resistansinya anatara lain adalah kontaminasi pengotor berupa garam yang terbawa angin dan debu pada bagian-bagian isolator yang dalam keadaan basah atau lembab pengotoran ini akan membuat jalur konduktif pada permukaan isolator. semakin besar kontaminasi pengotoran pada isolator maka arus bocor yang mengalir juga akan semakin besar[4] [5][6].

\section{METODE PENELITIAN}

Arus bocor adalah arus yang mengalir dipermukaan bahan isolir akibat dari kerusakan bahan isolasi dan tidak terdapatnya sistem grounding pada body peralatan yang bertegangan[7]. Dampak yang ditimbulkan dari mengalirnya arus bocor adalah ketika sesorang menyentuh body dari peralatan bertegangan maka arus bocor tersebut akan mengalir ke tubuh menuju ground. Jadi badan kita menjadi perantara antara body dan ground. Dampak luas yang dapat ditimbulkan adalah terjadinya konsleting listrik yang dapat menimbulkan kebakaran jika tidak diatasi.

Sensor SCT013 adalah sensor arus bolakbalik yang menggunakan konsep cara kerja trafo arus. Sensor ini dapat mengukur arus AC sampai 100 Amper sehingga banyak digunakan di Industri, otomotif, komersil dan sistem komunikasi.

Sensor ini dipasang dengan cara dijepit pada bagian negatif elektroda bola. Arus bocor yang melalui elektroda positif menuju elektroda negatif yang terhubung dengan sistem pentanahan akan terdeteksi oleh sensor ini. Sensor akan mengirim sinyal digital ke mikrokontroller nodeMCU ESP8266yang kemudian diubah menjadi besaran elektrik yang dapat dimonitor melalui lcd dan perangkat interface lainnya. Pada penelitian ini menggunakan thingspeak sebagai platform interface monitoring arus bocor isolator. Thingspeak merupakan open source "internet of things" aplikasi dan API untuk menyimpan dan mengambil data dari hal-hal yang menggunakan HTTP melalui Internet atau melalui Lokal Area Network.

Unsur utama dari kegiatan ThingSpeak adalah saluran, yang berisi bidang data, bidang lokasi, dan bidang status. Setelah kita membuat saluran ThingSpeak, kita dapat menulis data ke saluran, proses dan melihat data dengan kode MATLAB, dan bereaksi terhadap data dengan tweet dan alert lainnya.

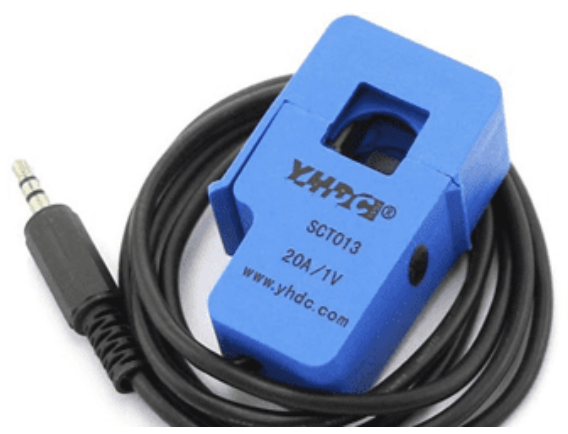

Gbr.1 Sensor Arus SCT013-100

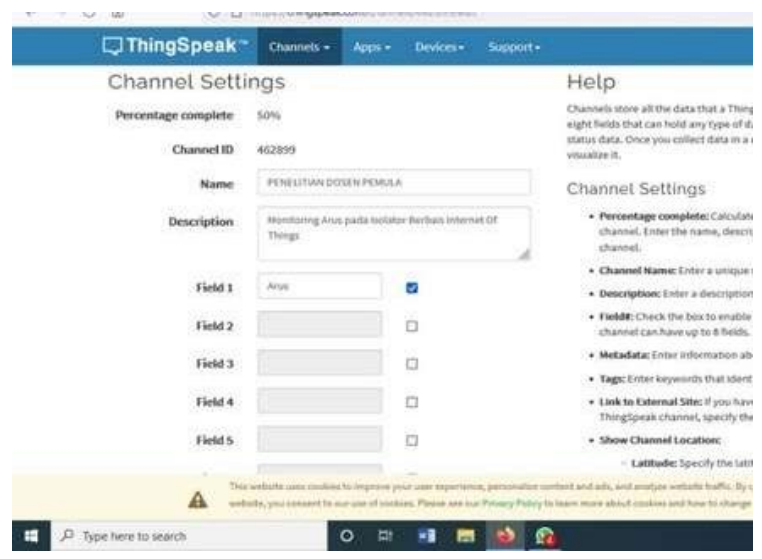

Gbr.2 Pengaturan channel setting Thingspeak

Visualisasi besaran arus yang terukur dapat ditampilkan dalam bentuk grafik dan nilai arusnya dapat dikompilasi dalam bentuk tabel Excel. Pengukuran arus disetiing per lima menit selama kurang lebih satu jam pengujian arus bocor isolator. 
Alat dan bahan yang digunakan pada penelitian ini antara lain :

1. Sensor Arus CST013

2. NodeMCU ESP 8266

3. Multimeter

4. Peralatan Pengujian Tegangan Tinggi

5. Isolator Gantung

Program pendukung yang digunakan adalah Arduino IDE dan ThingSpeak. Berikut diagram blok sistem dari rancangan sistem monitoring arus bocor.

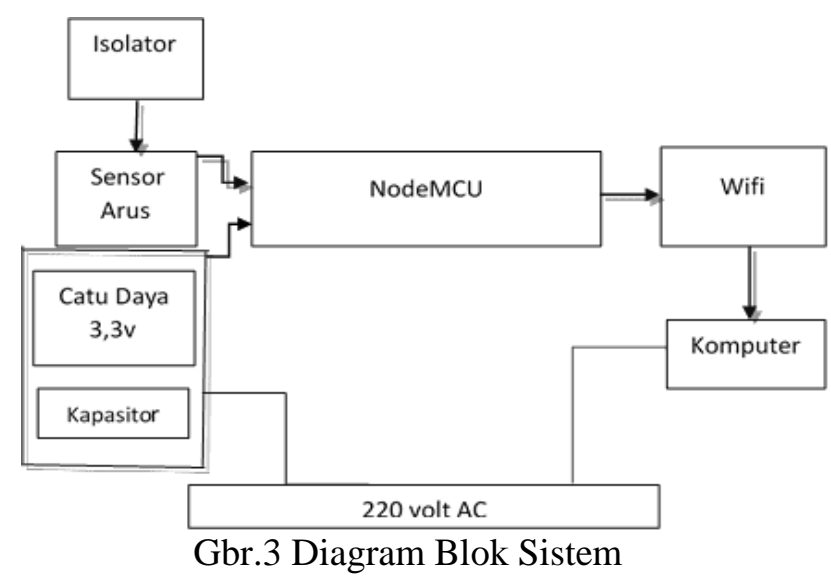

Inputan nodeMCU berupa sensor arus, catu daya yang digunakan adalah power bank, outputanya adalah pembacaan nilai arus di thingspeak yang dapat diakses melalui jaringan internet/wifi laptop.

\section{ANALISA DATA}

\section{A. Perancangan Prototipe Real Time \\ Monitoring Arus Bocor Isolator}

Perancangan prototipe terbagi menjadi 2 bagian yakni perancangan perangkat keras dan perancangan perangkat lunak. Realisasi rancang bangun sistem monitoring arus bocor dapat dilihat pada gambar 4 di bawah.

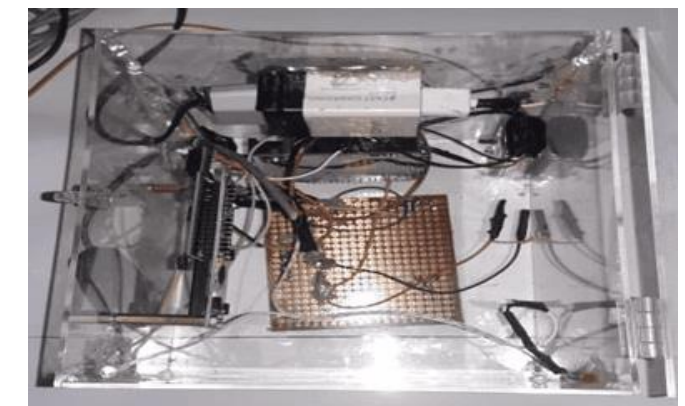

Gbr.4 Perangkat keras monitoring arus bocor isolator.
B. Instalasi sensor arus pada peralatan tegangan tinggi

Pemasangan sensor arus CST013-100 pada peralatan tegangan tinggi yakni dibagian negatif elektroda bola seperti yang terlihat pada Gambar 5.

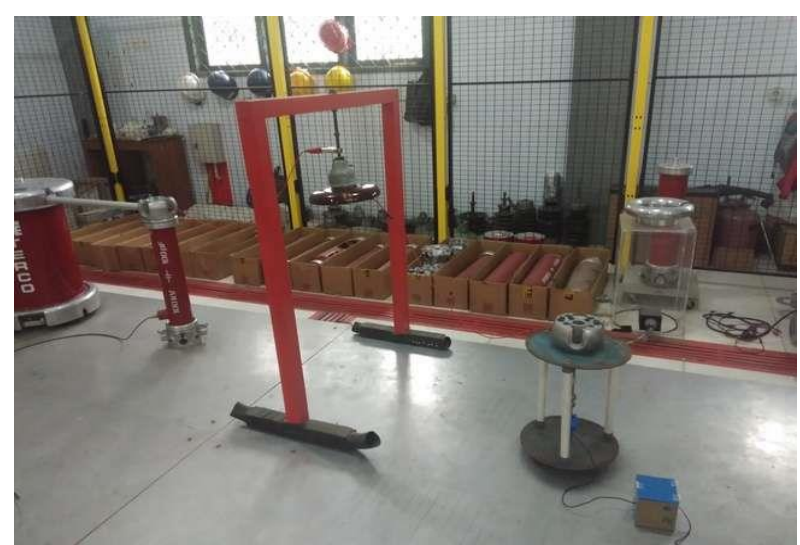

Gbr.3 Instalasi sensor pada elektroda bola

\section{Analisa Data Hasil Pengukuran Arus Bocor}

Pengukuran arus bocor isolator dilakukan dengan pengujian tegangan tinggi AC yakni dengan menggantung isolator uji yang terhubung dengan trafo pengujian, kapasitor dan resistor tegangan tinggi setelah itu tegangan dinaikkan secara bertahap sampai terjadi percikan pada sela elektroda bola. Arus bocor akan mulai terbaca ketika tegangan yang diberikan pada isolator semakin meningkat. Berikut data hasil pengukuran arus bocor menggunakan multimeter.

Tabel 1. Pembacaan Arus di Multimeter

\begin{tabular}{|c|c|c|c|}
\hline No & $\begin{array}{c}\text { Time } \\
\text { (Second) }\end{array}$ & $\begin{array}{c}\text { Tegangan } \\
(\mathbf{k V})\end{array}$ & $\begin{array}{c}\text { Arus } \\
(\mathbf{A})\end{array}$ \\
\hline $\mathbf{1}$ & $18: 05: 24$ & 35 & 0,023 \\
\hline $\mathbf{2}$ & $18: 09: 44$ & 50 & 0,218 \\
\hline $\mathbf{3}$ & $18: 13: 16$ & 70 & 1.922 \\
\hline
\end{tabular}

Pengujian dilakukan mulai dari tegangan terkecil yakni $5 \mathrm{kV}$ dan terus dinaikkan sampai terjadi flashover pada isolator. Arus bocor mulai terukur pada level tegangan pengujian $35 \mathrm{kV}$ ditahan selama 25 menit kemudian dinaikkan di tegangan $50 \mathrm{kV}$ 
ditahan selama 4 menit, lalu dinaikkan sampai $70 \mathrm{kV}$ dan ditahan selama 4 menit. Tujuan dari dinaikkannya level tegangan pengujian yakni guna melihat pengaruh tingkat tegangan yang dikenakan pada isolator terhadap besarnya arus bocor dan ditegangan berapa isolator mengalami flashover.

Pada saat terjadi flashover arus bocor naik secara signifikan yakni 1,922 Ampere dibandingkan arus bocor sebelum terjadi flashover. Pada Tabel 2 disajikan arus bocor dari hasil pembacaan sensor yang telah dikompile ke excel. Arus bocor mulai terbaca dari pukul 17.41.24 dan pengujian diakhiri pada pukul 18.13.16, settingan waktu pembacaan arus di thingspeak diatur per satu menit lima detik.

Tegangan tinggi bolak balik yang dikenakan pada isolator uji mulai dari $5 \mathrm{kV}$ ditahan selama 1 menit kemudian dinaikkan di level $10 \mathrm{kV}$ ditahan lagi selama 1 menit terus menerus dinaikkan sampai mulai terbaca arus bocor pada level $35 \mathrm{kV}$ sebesar 0,001 A dimenit 17.41.24 dan nilai arus bocornya semakin meningkat seiring lamanya pemberian tegangan dan level tegangan yang lebih tinggi. Isolator mengalami tembus tegangan di level $70 \mathrm{kV}$ besar arus terbaca 1,932 Ampere.

Berikut tabel 3 menyajikan rangkuman hasil pembacaan arus bocor isolator dengan multi meter dan sistem monitoring di satu sampling waktu pada setiap level tegangan uji.

Dari gambar 4 di atas diketahui bahwa besarnya kenaikan arus sebanding kenaikan tegangan uji isolator. adapun selisih arus di 3 sampel waktu pengambilan data jika dipersentasekan arus bocor pembacaan sensor sebesar 3,2\%, 10,8\% dan 31,0\% lebih besar daripada arus pembacaan multimeter.
Tabel 2. Arus Pembacaan Sensor

\begin{tabular}{|c|c|c|c|}
\hline \multirow[t]{2}{*}{ No } & \multirow{2}{*}{$\begin{array}{c}\text { Time } \\
\text { (Second) }\end{array}$} & \multicolumn{2}{|c|}{ Keterangan } \\
\hline & & $\begin{array}{l}\text { Arus Bocor } \\
\text { (A) }\end{array}$ & $\begin{array}{c}\text { Tegangan } \\
\text { Uji } \\
\end{array}$ \\
\hline 1 & $17: 41: 24$ & 0.001 & \multirow[t]{25}{*}{$35 \mathrm{kV}$} \\
\hline 2 & $17: 42: 29$ & 0.001 & \\
\hline 3 & $17: 43: 34$ & 0.001 & \\
\hline 4 & $17: 44: 39$ & 0.001 & \\
\hline 5 & $17: 45: 44$ & 0.001 & \\
\hline 6 & $17: 46: 49$ & 0.007 & \\
\hline 7 & $17: 47: 54$ & 0.007 & \\
\hline 8 & $17: 48: 59$ & 0.007 & \\
\hline 9 & 17:49:04 & 0.007 & \\
\hline 10 & 17:50:09 & 0.012 & \\
\hline 11 & $17: 51: 14$ & 0.012 & \\
\hline 12 & $17: 52: 19$ & 0.013 & \\
\hline 13 & $17: 53: 24$ & 0.015 & \\
\hline 14 & $17: 54: 29$ & 0.016 & \\
\hline 15 & $17: 55: 34$ & 0.016 & \\
\hline 16 & $17: 56: 39$ & 0.021 & \\
\hline 17 & $17: 57: 44$ & 0.021 & \\
\hline 18 & $17: 58: 49$ & 0.023 & \\
\hline 19 & $17: 59: 54$ & 0.023 & \\
\hline 20 & 18:00:59 & 0.023 & \\
\hline 21 & 18:01:04 & 0.023 & \\
\hline 22 & 18:02:09 & 0.024 & \\
\hline 23 & $18: 03: 14$ & 0.024 & \\
\hline 24 & 18:04:19 & 0.025 & \\
\hline 25 & 18:05:24 & 0.025 & \\
\hline 26 & 18:06:29 & 0.025 & \multirow[t]{4}{*}{$50 \mathrm{kV}$} \\
\hline 27 & 18:07:34 & 0.050 & \\
\hline 28 & 18:08:39 & 0.134 & \\
\hline 29 & 18:09:44 & 0.426 & \\
\hline 66 & 18:10:01 & 0.212 & \multirow[t]{4}{*}{$70 \mathrm{kV}$} \\
\hline 67 & 18:11:06 & 1.210 & \\
\hline 68 & 18:12:11 & 1.740 & \\
\hline 69 & $18: 13: 16$ & 1.932 & \\
\hline
\end{tabular}

Tabel 3. Perbandingan Arus Multimeter dan Sensor Arus CST013

\begin{tabular}{|c|c|c|c|c|}
\hline \multirow{2}{*}{ No } & \multirow{2}{*}{$\begin{array}{c}\text { Time } \\
\text { (Second) }\end{array}$} & $\begin{array}{c}\text { Tegangan } \\
\text { Uji }(\mathbf{k V})\end{array}$ & $\begin{array}{c}\text { Multi } \\
\text { Meter } \\
(\mathrm{A})\end{array}$ & $\begin{array}{c}\text { Sistem } \\
\text { Monitoring } \\
(\mathrm{A})\end{array}$ \\
\hline $\mathbf{1}$ & $18: 05: 24$ & 35 & 0.023 & 0.055 \\
\hline $\mathbf{2}$ & $18: 09: 44$ & 50 & 0.318 & 0.426 \\
\hline $\mathbf{3}$ & $18: 13: 16$ & 70 & 1.622 & 1.932 \\
\hline
\end{tabular}


Tabel 4. Selisih Nilai hasil pembacaan multimeter dan Sensor Arus

\begin{tabular}{|c|c|c|c|c|}
\hline \multirow{2}{*}{$\mathrm{N}$} & \multirow{2}{*}{$\begin{array}{c}\text { Tegangan } \\
\text { Uji } \\
(\mathrm{kV})\end{array}$} & $\begin{array}{c}\text { Multi } \\
\text { Meter } \\
(\mathrm{A})\end{array}$ & $\begin{array}{c}\text { Sistem } \\
\text { Monitoring } \\
(\mathrm{A})\end{array}$ & $\begin{array}{c}\text { Selisih } \\
\text { Arus } \\
(\mathrm{A})\end{array}$ \\
\hline $\mathbf{1}$ & 35 & 0,023 & 0,055 & 0,032 \\
\hline $\mathbf{2}$ & 50 & 0,318 & 0,426 & 0,108 \\
\hline $\mathbf{3}$ & 70 & 1,622 & 1,932 & 0,310 \\
\hline
\end{tabular}

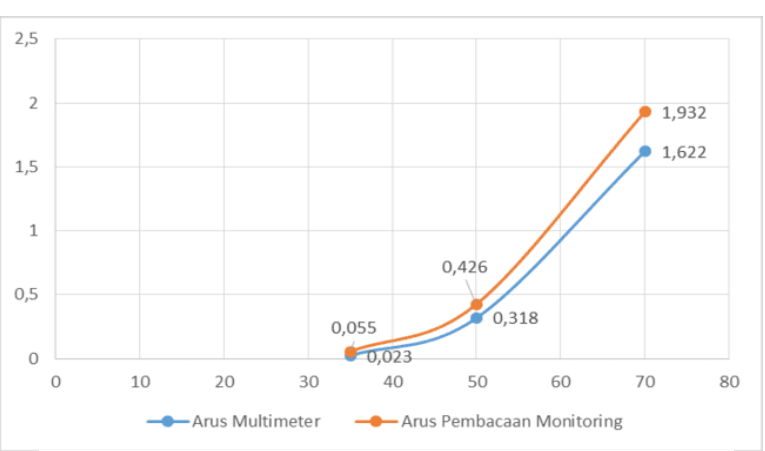

Gbr.4 Kurva Perbandingan arus pembacaan multimeter dan monitoring arus

\section{KESIMPULAN}

Berdasarkan hasil analisa data di atas dapat disimpulkan bahwa sensor arus dapat mengukur arus bocor isolator dari nilai minimum mulai mengalirnya arus sampai arus terbesar saat terjadi flashover. Data yang diperoleh dapat diatur waktu pembacaannya sehingga memudahkan pengambilan data arus. Meskipun terdapat selisih antara pembacaan multimeter dan sensor namun selisihnya tidak besar yakni kurang dari $50 \%$. Kenaikan arus bocor isolator sebanding dengan lamanya waktu pemberian tegangan uji dan besarnya tegangan uji sampai isolator flashover.

\section{UCAPAN TERIMA KASIH}

Terimakasih kami ucapkan kepada Kepala dan Laboran Tegangan Tinggi Universitas Negeri Gorontalo yang telah meluangkan banyak waktu untuk mendapingi kami selama pengambilan data berlangsung. Juga kepada rekan-rekan sejawat yang selalu sedia bertukar pikiran dan berbagi pengalaman keilmuannya. Kepada lembaga penelitian Universitas Ichsan Gorontalo yang senantiasa membantu dalam administrasi persuratan.

\section{REFERENSI}

[1] A.S. Handayai, A.Priyadi, dan R.Mardiyanto, "Deteksi dini arus bocor pada kabel Screen Untuk Mencegah Hubung Singkat Pada Kabel Tanah Mengunakan Mikrokontroler," Thesis, ITS, 2014.

[2] T. Nusa, S. R. U. A. Sompie, and E. M. Rumbayan, "Sistem Monitoring Konsumsi Energi Listrik Secara Real Time Berbasis Mikrokontroler," J. Tek. Elektro dan Komput., vol. 4, no. 5, pp. 19-26, 2015, doi: 10.35793/jtek.4.5.2015.9974.

[3] D. Handarly and J. Lianda, "Sistem Monitoring Daya Listrik Berbasis iot (Internet of Thing)," JEECAE (Journal Electr. Electron. Control. Automot. Eng., vol. 3, no. 2, pp. 205-208, 2018.

[4] Jumrianto, Wahyudi, and A. Syakur, "Design and development of data acquisition for leakage current at electrical tracking test," in Proceedings - 2017 4th International Conference on Information Technology, Computer, and Electrical Engineering, ICITACEE 2017, 2017, vol. 2018-January.

[5] A. Banik, S. Dalai, and B. Chatterjee, "Autocorrelation aided rough set based contamination level prediction of high voltage insulator at different environmental condition," IEEE Trans. Dielectr. Electr. Insul., vol. 23, no. 5, 2016.

[6] A. Ashari, A. Syakur, B. Winardi, and L. Belakang, "Analisa Pengaruh Kontaminsai Pantai Terhadap Unjuk Kerja Sampel Isolator Bahan Keramik Sebelum dan Sesudah Dilapisi Minyak Silikon," Jurnla Transmisi, Vol.14, No. 4, 2012

[7] P. Mangera and Jayadi, "Analisis Hubungan Arus Bocor Dan Penyebabnya Terhadap Kerugian Pembayaran Rekening Bulanan Konsumen Instalasi Rumah Tangga Pada Pt.Pln (Persero) Cabang Merauke," Jurnal Ilmiah Mustek Anim Ha, vol. 1, no. 1, pp 50-60, 2012. 